\title{
Educación y prensa en el contexto electoral: Un estudio comparado Argentina, Brasil y México*
}

Virgilio Alvarez Aragón**

RESUMO: O artigo tenta analisar a importância que a imprensa latino-americana outorga à educação e o impacto que tais matériais poderiam ter na população nos momentos eleitorais. Levando em conta a proposta teórica dos cenários de representação política, apresenta-se o que foram as temáticas mais importantes para a imprensa na Argentina, no Brasil e no México, no que diz respeito à educação, nos períodos prévios aos pleitos eleitorais, considerando para isso os distintos níveis de ensino e os diferentes tipos de notas.

Palavras-chave: educação e imprensa, educação na America Latina, educação e eleições, cenários de representação política, educação e hegemonia

\section{Introducción}

Dadas las condiciones en que la educación se encuentra en nuestro continente, su atención por parte del poder público es cada vez más un tema en las campañas electorales, especialmente en las propuestas de gobierno de los que se postulan al más alto cargo ejecutivo: la Presidencia de la República. De una u otra forma, los discursos de los candidatos hacen mención de la situación educativa existente y de sus propósitos por realizar algunas mudanzas, ofreciendo mejorarla y hacerla accesible a más amplios sectores de la sociedad.

Por otro lado, cada vez es más común la referencia al hecho que los medios de comunicación juegan un papel fundamental en la definición de

* Los datos y las informaciones que en este trabajo se presentan son producto de la investigación que realizamos dentro del plan de actividades que como bolsista recem doutor do CNPq desarrollamos en el bienio 1995-1996 en el área de confluencia Estado e Políticas Públicas del Programa de Posgraduação da Faculdade de Educação da Universidade de Brasília. Así mismos son consecuencia de nuestra participación en el GT Midia e Política da FA da UnB, coordinado por Venício da Lima.

** Professor adjunto, Departamento de Teoria e Fundamentos da Educação, Faculdade de Educação, Universidade de Brasília. 
los intereses y las decisiones electorales. En lo que se refiere a la educación, es de dominio público que las cuestiones referentes tanto a ésta como al sistema escolar en su conjunto no son objeto de interés permanente de la prensa. Sin embargo, partiendo del supuesto de que por poco que de ella se diga en los medios de comunicación escrita, de una u otra manera influye en la opinión de los distintos segmentos de la sociedad, en el presente trabajo intentamos considerar lo que en los diarios más importantes de tres países del continente publicaron sobre los temas educativos en los períodos previos a los procesos electorales. Con esa información intentaremos, en un primer momento, una breve descripción de los que fueron los temas más destacados y atendidos, para así establecer luego las posibles relaciones que surjan con los discursos electorales de los candidatos a la primera magistratura de tales países.

Si bien la prensa escrita tiene un alcance limitado en los países latinoamericanos, sus lectores habituales pertenecen a grupos sociales más o menos activos y participativos en las cuestiones políticas. Por tanto, lo que las notas y opiniones que en esos medios se transmitan influirán tanto en éstos como en sus allegados, desencadenando un conjunto de reacciones con relación a las situaciones presentadas, pudiendo llegar a tener incidencia en la orientación del voto.

Partimos del supuesto de que en los períodos preelectorales estos grupos sociales están mucho más atentos a lo que consideran sus necesidades dado que tienen en el horizonte inmediato la expectativa de solucionarlas, con lo que el papel de la prensa en la divulgación de hechos y opiniones sobre esas expectativas viene a cobrar mayor relavancia, ya que consideramos que lo que en ella se noticíe o deje de presentar vendrá a constituir el marco de referencia sobre el cual buen número de electores definirán sus simpatías.

Cierto es que la educación no constituye uno de los temas más polémicos de las campañas electorales, pero también lo es que en los últimos procesos no ha estado totalmente ausente, por lo que si bien no es un tema capital y central como lo han sido las cuestiones económicas, es parte integrante de la temática puesta en discusión en estos procesos, especialmente porque cada vez más los temas referidos a ella se incorporan a lo que bien podemos considerar como la construcción de las significaciones hegemónicas, estando presente no sólo como un discurso con dinámica propia, si no como integrante de lo que es la cultura dominante.

La construcción de las hegemonías proviene, según Gramsci (1971), de la aceptación de las relaciones de poder existentes, que son 
construídas a partir de representaciones simbólicas que, como lo propone Smith (1996), "crean y reflejan una visión de la realidad social que justifica el status-quo, al definir formas establecidas de dominación y subordinación como el orden natural de las cosas". La hegemonía, en la opinión de Lima (1995), es un sistema amplio, en el cual diversas dimensiones de la representación simbólica construyen lecturas dominantes de los aspectos de la vida cotidiana que se aceptan como ciertos y válidos, viniendo consecuentemente a orientar y definir las decisiones inviduales, que si bien analíticamente puede considerarse como un sistema o una estructura es, en palabras de Williams (1979, p.115) un proceso, "un complejo realizado de experiencias, relaciones y actividades".

Como proceso, la hegemonía se transforma en su sentido más fuerte en una cultura en la cual la dominación y la subordinación se determinan y explican, siendo, como también lo afirma Williams (ibid.) continuamente resistida, limitada y desafiada, por lo que constantemente debe ser renovada, recriada, defendida y modificada.

Así, dentro de esta concepción de la hegemonía, el concepto de escenarios de representación $E R^{1}$ cobra una función altamente explicativa, util a la reflexión que pretendemos llevar a cabo, pues constituyen espacios, multiples, variados y entrelazados, en los que las acciones, o parte de ellas, se realizan. En términos de Lima (1994), la hegemonía puede ser descompuesta en varios escenarios - espacios de realización - que necesariamente incorporan todas las características de la hegemonía, que si bien es en términos más ampl ios de carácter político, posee momentos y dimensiones particulares, por lo que es posible hablar de escenarios de representación de raza, género, ciencia, educación etc., los que si bien posen su própria significación y alcance, en última instancia se entrelezan, complementan y hasta se contraponen com la dimensión política.

Supónese así que, esos escenarios específicos, de manera dinámica - influyentes e influídos - se asocian e integran con el escenario de representación política, dado que éste es el que afianza y da soporte a las estructuras de poder y dominación, que definen y garantizan la hegemonía. El concepto de ER-P resulta, así, mucho más amplio en su comprensión metodológica que otros utilizados tradicionalmente para explicar los comportamientos electorales. ${ }^{2}$

Esos múltiples escenarios, en una sociedad determinada cada vez más por los medios de comunicación de masas, tienen su principal fuente de construcción, según autores especializados (Lima 1994, 1995; Porto 
1995; Smith 1996), en los medios televisivos, viniendo a constituir lo que Sartori (1989) ha dado en llamar una videopolítica.

El aporte de Lima $(1994,1995)$ se considera esclarecedor por que fuera de explicaciones maniqueas y deterministas, sugiere que contenidos propios de contra hegemonías e inter hegemonías tienen la posibilidad de manifestarse en los medios de comunicación de masa, permitiendo la posibilidad de constitución de contra e inter escenarios de representación política que desafian o cuestionan al dominante, ya desde posiciones externas al bloque en el poder (contra hegemónicos) ya desde dentro de los mismos (intra hegemónicas) en un proceso en el cual, claro está, las rupturas son menos posibles que la tendencia a la continuidad, que de por sí se ve condenada a una constante evolución y mudanza. ${ }^{3}$

El concepto de ER-P conduce a considerar además, que su constitución no se funda simplemente en la transmisión de las cuestiones meramente politicas en los espacios dedicados a ellas, si no por todo el conjunto de elementos que los medios de comunicación divulgan. Valiosos resultan así los estudios que dentro de esta perspectiva han sido realizados sobre los melodramas brasileños, tal el caso de los hechos por Porto (1995), en los que es posible descubrir cómo en la televisión brasileña la cuestión política está mucho más presente que en otras realidades, producto, consideramos, de la forma en que los escenarios de representación se han ido construyendo. ${ }^{4}$

La posibilidad de mudanza constante en el ER-P hegemónico, así como la expectativa de que otros ER puedan cuestionar y desafiar el domininante, hace del concepto una categoría de análisis dinámica, pues viene a considerar la construcción social de los significados, con resultados y consecuencias inesperadas, producto y causa de la conjunción de acciones racionales individuales, que para el caso de los medios de comunicación de masas, no son simplemente los autores y directores de las programaciones y publicaciones por ellos difundidas, si no todos aquellos que dan vida y forma a los mensajes (actores, comentaristas, presentadores, editores etc.) que pueden o no estar convencidos de los valores y concepciones integrantes del ER-P dominante. ${ }^{5}$

La constitución de ER-P es por tanto un concepto que si bien se refiere a situaciones colectivas, no asume como posibles las explicaciones simples que asocian el comportamiento de los medios de comunicación de masas a una "voluntad invisible" que lo define y lo integra, si no se le ve como producto del conjunto de contradicciones que en una sociedad 
determinada puedan encontrarse, estando abierto, por tanto, a la constante presión de inter y contra elementos simbólicos que, de no ser asimilados, pueden dar lugar a nuevos escenarios contra hegemónicos o, en lo mínimo, recomposiciones de las hegemonías dominantes.

La idea, por detrás de toda esta elaboración, es que el candidato ganador en determinado proceso electoral, más que productor y creador de su imagen es aquel que logra "adecuar su perfil y sus propuestas al ER-P dominante", o, como lo dice Smith (1996, p. 148), aquel que logra que "la presentación de sí mismo coincida o se adapte con el ER-P existente", 6 o pueda construir un ER-P alternativo dentro del mismo discurso hegemónico, como fue el caso de Fernando Henrique Cardoso.

Desde esta perspectiva, los medios de comunicación escrita, si bien no son considerados claves en la construcción y desconstrucción de hegemonías, consideramos que no resultan ajenos a tales procesos, dado que de multiples maneras se hacen presente con revelaciones y explicaciones del diario acontecer de una sociedad, siendo aún considerados como fuente de información por un amplio sector de la población. Ello permite considerar que puedan ser considerados como parte activa en la construcción de los ER-P, aunque de manera menos intensa que los medios televisivos, pero también de una forma más independiente, lo que si bien nos lleva a establecer que no son los definidores de tales escenarios, el análisis de los mismos no debe olvidarlos, pudiendo por tanto ser parte de la construcción de las contra hegemonías o, en la mayoría de los casos, de propuestas alternativas dentro del mismo discurso hegemónico, ${ }^{7}$ comportamiento que constituye la base de nuestro estudio.

Esa relativa importancia deviene de su capacidad para poner en circulación temáticas que, perteneciendo al mundo de las expectativas e intereses presentes de los lectores, en los momentos electorales pueden llegar a convertirse en centrales dentro del abanico de justificativas que, como electores, vengan a considerar en el momento de definir su voto.

El concepto de ER-P además, incluye y supera al de cultura política - CP - y no simplemente lo niega, pues tiene implícita, como éste, la importancia que la prensa puede jugar en la constitución de las hegemonías, especialmente cuando se ponen en acción elementos que permitan pensar que una CP participativa ${ }^{8}$ está constituyéndose ${ }^{9}$ en una sociedad determinada.

Como parte de los medios de comunicación masiva, la prensa contribuye, aunque en menor escala que la televisión, a que los procesos 
de identificación política se lleven a cabo, sirviendo de vehículo en la lucha por el control de los conocimientos y sus significados, al "constituir/reflejar", como lo afirma de Lima (1994, p. 67), los ámbitos donde las diferentes cuestiones vitales de la sociedad son definidas. Al definir los temas prioritarios, insiste, "fijan los límites estructurales en los que se llevará a cabo el proceso electoral". Tal definición de temáticas, ampliamos nosotros, no responde, en los procesos de consolidación democrática, simplemente a la dinámica unidireccional de los intereses de los medios de comunicación, ya que éstos deben, a cada momento, abrirse a las exigencias y demandas del consumidor de informaciones, que se resiste cada vez más a comportarse como sujeto pasivo del proceso de comunicación, con lo que la interacción usuario/medios viene a ser cada vez más fuerte e intensa. ${ }^{10}$

Es esta dialéctica la que tratamos de identificar en el presente estudio. Si bien la prensa puede definir de alguna forma los temas educativos que tendrán que ser discutidos y presentados en la disputa electoral, su selección parte de lo que es en términos generales las expectativas de algunos sectores de la sociedad. No nos es posible reconstruir la génesis de la información, mucho menos las razones que conducen a los editores a seleccionar una u otra información; sin embargo, si asumimos que la prensa necesita atender su mercado, es válido suponer que las noticias presentadas son las que se consideran de interés para el lector.

En nuestro caso, por lo tanto, nos concentraremos en intentar descubrir las temáticas educativas más difundidas, para luego tratar de encontrar sus correlatos en el discurso electoral. La constatación de coincidencias permitiría pensar en cierta sintonía entre prensa y política y, el que las mismas estuviesen presentes en los discursos de determinados candidatos, su importancia en la constitución de uno u otro escenario de representación.

La prensa escrita y sus posibilidades en la creación de ER-P

Lo dicho anteriormente con relación a la prensa escrita adquiere mayor importancia si tomamos en cuenta que, en las condiciones particulares de Argentina, Brasil y México, el ocaso político de la misma ante la importante penetración de la televisión es aún lejano, tanto por la importancia que en la historia reciente ha tenido, como por el papel de independencia que en los últimos años ha manifestado. 
En el pasado reciente, cuando tanto Argentina como Brasil se encontraban sumidos en procesos autoritarios y represivos, la televisión fue marcadamente acrítica, en un caso por ser controlada y dirigida directamente por el aparato estatal y en el otro porque, siendo privada, la principal cadena de televisión Globo, necesitaba del apoyo del régimen para mantener su monopolio, construido al amparo y protección del gobierno militar. En el caso de México, si bien la televisión de gran alcance era privada y no se vivía bajo régimen militar, el proceso de centralización que el régimen de partido único mantenía hizo que la cadena privada Televisa se mostrase, más que una cadena oficiosa, como un apéndice de la política inclusiva/autoritaria del Estado. ${ }^{11}$

Ante ese panorama, la prensa escrita jugó un papel significativamente distinto, que en las elecciones reciente puede ser considerado como de alta madurez para los casos argentino y brasileño, posiblemente porque desde los años de la dictadura la prensa escrita no permaneció totalmente atada a las decisiones del régimen. Ejemplar es, en ese sentido, el papel que periódicos como la Folha de S. Paulo jugaron en el Brasil en el proceso que desembocó en la lucha por la democratización y que es conocido como de las "diretas já". ${ }^{2}$ Si bien esa actitud no tiene correlatos en la realidad Argentina (Waisbord 1995) la actitud de Clarín - abiertamente opositor a la política económica de la dictadura - y de La Prensa - que enfrentó al gobierno en cuestiones de derechos humanos - merecen especial atención, pues muestran los intentos de la prensa escrita por ganar espacios.

Puede suponerse por lo tanto que, mientras el discurso y los contenidos que hacen parte del escenario político hegemónico tiene en los medios televisivos su principal soporte, los escenarios contra hegemónicos han encontrado, en los países en estudio, un apoyo sustantivo en la prensa escrita, si no en toda, al menos en un sector significativo de ella. Es posible hipotetizar, además, de que ello fue posible porque en estos países resultaron ineficaces los esfuerzos por instituir periódicos vinculados directamente a los partidos, ${ }^{13}$ viniendo a ser apreciado cada vez más el modelo norteamericano de objetividad de la prensa apartidaria, que el europeo, en el que la prensa de partido tiene una significación importante en la discusión política. ${ }^{14}$

Valga aclarar que para el caso mexicano, si bien no existen periódicos de partido, la posibilidad del alejamiento de la prensa con el aparato gubernamental ha sido más lento y difícil, dado las características del régimen mexicano: durante años la prensa funcionó como vocera y defensora del partido oficial y gobernantes, las simples tenta- 
tivas de disenso eran castigadas con el recorte de "propaganda oficial" y con acciones al interior de los propios periódicos para "castigar" a los opositores. ${ }^{15}$ Sin embargo, luego de los trágicos sucesos de 1968 y especialmente a partir del segundo lustro de los años ochenta, esfuerzos de prensa independiente fueron consolidándose, con lo que la información dejó de ser necesariamente oficiosa, abriéndose cada vez más a opiniones de disenso y críticas. La consolidación de revistas de oposición como Proceso y el afianzamiento de diarios abiertamente independientes como La Jornada vinieron a dar un matiz diferente a la prensa mexicana. ${ }^{16}$

Posiblemente este comportamiento no haya sido simplemente producto de la vocación democrática de los medios, pudiendo estar influido por la necesidad que el mercado impone cuando los procesos de democratización se producen: los lectores/electores demandan mayor y mejor información y los medios, para sobrevivir, necesitan cubrir las demandas crecientes de los mismos. ${ }^{17}$ Dejar de ser simples voceros o defensores de los gobiernos, manifestar independencia y criticidad, resultan imperiosas necesidades para su sobrevivencia en un espacio cada vez mas exigente; si el televidente cuando se enfrenta con lo que no gusta puede desviar la atención sin apagar el televisor, el lector de un periódico deja simplemente de comprarlo, con lo que su comportamiento es mucho más directo contra el medio.

Así, mientras la televisión continuaba en algunos casos abiertamente progubernamental, como es el caso de México, o relativamente prooficial, acrítica o tímida en términos de información política como es el caso argentino, ${ }^{18}$ la prensa escrita se empeñó en los últimos procesos electorales, con diversos matices según el país, en ser más independiente y objetiva. Esta práctica no fue inaugurada en las elecciones pasadas, aunque es innegable que es de origen reciente. En Brasil tiene sus primordios en la lucha por elecciones presidenciales directas en 1984 y alcanzó su mayor expresión cuando las denuncias por corrupción contra el gobierno Collor en 1992, siendo ejemplares en ese sentido los comportamientos de los principales diarios paulistas: Folha y Estado de S. Paulo. En Argentina puede datarse a partir de la crítica del diario Clarín a la política económica del gobierno Alfonsín, alcanzando su más clara independencia en el proceso electoral recién concluído. En México, por su lado, si bien los esfuerzos son de más larga data, no es sino durante el gobierno del presidente Salinas que los diarios - especialmente los más nuevos como La Jornada, El Financiero y Reforma - logran convertirse en espacios de crítica al régimen vigente. 
Prensa y educación

Considerando ese conjunto de características resulta claro que para los intereses de nuestro estudio tales medios resultan importantes, pues siendo responsables en alguna medida por la constitución de los Escenarios de Representación Política, al actuar directamente en la posible construcción de discursos y culturas intra y hasta contrahegemónicas, es posible suponer que el tema educativo sea más atendido en sus páginas que en los noticieros y programaciones televisivas en general. La intensidad, temáticas y formas en que las cuestiones relacionadas con la educación sean presentadas vendrían por tanto, según nuestros supuestos, a configurar y delimitar con mayor claridad ese tipo de escenarios.

La prensa en los distintos países estuvo marcada en los períodos previos por temas mucho más álgidos y polarizantes que las propias cuestiones educativas, básicamente las cuestiones económicas y los propios procesos electorales $;^{19}$ sin embargo, algunas notas sobre temas educativos fueron publicadas en ese período, por lo que si bien no ganó las primeras planas ni titulares sensacionales, sí se mantuvo vigente entre los intereses generales de los lectores.

Tomando en cuenta las delimitaciones anteriores, nuestro trabajo tuvo como punto de referencia inicial las materias que los distintos diarios circularon entre sus lectores en los meses previos a la realización de los pleitos electorales y que de una u otra forma hacen referencia a cuestiones educativas. Para el caso brasileño se consultaron cuatro de los diarios considerados de circulación nacional: O Globo, Folha de S. PauIo, Estado de S. Paulo y Jornal do Brasil, así como otros tres de influencia más local; ${ }^{20}$ para el caso argentino fueron consultados los diarios $\mathrm{La}$ Nación, Clarín y Página 12; por su parte, para el caso de México, se usaron como fuentes los diarios La Jornada, El Universal y Excelsior. ${ }^{21}$ Una presentación detallada de la cantidad de notas publicadas por los diarios aparece en el Cuadro I.

En total fueron analizadas 1.340 notas, de las cuales 750 corresponden a la prensa brasileña. Es notorio, sin embargo, que fue en la prensa argentina donde más notas referidas a la educación se publicaron por mes, casi el doble que en Brasil y 0,39 veces más que en México (ver Cuadro I). Tanto en el caso argentino como mexicano, diarios como La Nación y Universal dedicaron, casi diariamente, una sección propia 
para la educación que puede llegar a abarcar de media a una página del diario, cosa que no se percibe en la prensa brasileña donde, si existe las sección, ésta no tiene mayor regularidad.

En el caso mexicano, si bien La Jornada es quien más notas dedicó a los temas educativos, la extensión de las mismas es mucho menor que las de El Universal, ${ }^{22}$ donde los temas son tratados con mayor profundidad. Este dato resulta significativo, si consideramos que tanto La Jornada en México como Página 12 en Argentina representan un tipo de periodismo un poco diferente al tradicional pues, dedicados a un público más definido y reducido, concentran su interés en las cuestiones político-económicas, ${ }^{23}$ con notas que en su mayoría incluyen una fuerte dosis de opinión por parte de los reporteros, pudiendo ser considerados diarios de centro-izquierda. Sin embargo, para el caso de las notas educativas, la mayoría de ellas aparecen sin mayor opinión, dentro de una columna llamada Agenda educativa.

Visto por separado, en Brasil resulta significativa la importancia que $O$ Globo y Folha de S. Paulo dieron a la educación, pues en los diez y ocho meses en que fueron trabajados, produjeron promedios de 16,4 y 13,2 notas mensuales respectivamente. Puede considerarse como explicación que en los primeros seis meses, en los que sólo fueron estudiados esos diarios, los temas educativos fueron mucho más polémicos y demandaron más atención, lo que de ser cierto vendría a indicar que luego de iniciado el año electoral la educación perdió importancia para los diarios, y en consecuencia para los lectores. Aceptando ese razonamiento, resulta notorio que el comportamiento de la prensa argentina y mexicana se vieron menos limitadas a publicar notas al respecto de la educación en los meses más próximos a las elecciones, ya que las proporciones de sus notas fueron más altas que en Brasil en un período semejante.

Énfasis diversos según los niveles educativos

Para un primer análisis las notas fueron agrupadas a partir del nivel de educación al que se referían de manera explícita, fuese este básico, medio - segundo grau - para el Brasil - y superior; para los casos en que eso no sucedía, se creó un apartado propio, llamado Cuestiones Generales sobre Educación, en el que se incluyeron todas aquellas notas que hacían referencia a la educación como un hecho general o a varios niveles educativos al mismo tiempo. 
Como se puede ver en el Cuadro II, fue la educación superior el nivel que mayor número de notas periodísticas concentró en los tres países, ${ }^{24}$ sobresaliendo en ese sentido el énfasis que la prensa mexicana le dedicó. En este caso no todas ellas fueron dedicadas a cuestiones educativas específicamente, ya que buen número de las mismas se referían a la visita de los candidatos a la Presidencia de la República a campus universitarios, momentos en los cuales, entre otras cosas, éstos hicieron mención de sus propuestas sobre la educación superior.

En el caso de Brasil, gran número de las notas se refirieron a la realización y resultados de los exámenes vestibulares ${ }^{25}$ mostrando que el acceso a las Universidades, públicas en especial, es seguido con interés no sólo por los concursantes, si no también por sus próximos, usuarios potenciales de los periódicos escritos. Al no existir, en los otros dos países en estudio procesos semejantes, el interés que la prensa dedica a los mismos resulta una cuestión particular del caso brasileño.

En este mismo caso, casi todos los diarios dedicaron la misma proporción de notas a la educación superior - del total de notas que tuvieron como referente a la educación - pues, como en el Cuadro III.2 se muestra, mientras en el diario que más notas dedicó a ese nivel el porcentaje fue del $32 \%$ - el Estado de S. Paulo - el que menos interés le prestó - O Globo - dedicó el $26,4 \%$ de todas sus notas sobre educación al nivel superior. Puede concluirse, por lo tanto, que en este caso la educación superior fue casi igualmente atendida por todos los diarios consultados, absorbiendo casi la tercera parte de las notas que los mismos dedicaron individualmente a la educación como un todo.

Ese comportamiento no lo encontramos cuando de la educación básica se trata pues, como se muestra en el Cuadro III.1, mientras el diario que más atención le brindó fue $O$ Globo $(33,4 \%)$ otros se interesaron muy poco por ese nivel dedicándole, por ejemplo, el $14,7 \%$ de sus notas, como sucede con la Folha de $S$. Paulo. Así, si en términos generales la prensa brasileña tiene muestra un interés semejante para todos los niveles, ese comportamiento no se traduce directamente cuando el análisis es hecho considerando los diarios en particular.

Para los casos de Argentina y México, la situación es aún más polarizada. Mientras en el primer país educación superior y básica concentran casi todo el material producido por la prensa, en el segundo el énfasis fue puesto especialmente en el nivel superior. ${ }^{26} \mathrm{Si}$ el interés se traslada al comportamiento de cada uno de los diarios, notase que 
mientras diarios como La Nación y Jornada dedicaron casi la mitad de sus notas a la educación superior, disputan el mercado de lectores con otros que, como el caso de Página 12 en Argentina, dedicó más de la mitad de sus notas al primer nivel educativo (educación básica).

Pareciera, por lo tanto, que en algunos casos es posible hablar de diarios especializados en un nivel educativo particular. Página 12 en Argentina, por ejemplo, parece ser el diario de la educación básica, viniendo a interesarse por temas y situaciones que los otros diarios no consideran; situación semejante, aunque menos marcante, puede verse en Brasil con el caso de O Globo. Para el caso de la educación superior, tal afirmación puede hacerse para La Jornada en México y en menor grado con La Nación en Argentina.

De manera general puede afirmarse, por lo tanto, que "la educación superior fue la que más atención recibió de parte de todos los periódicos", al menos en los períodos pre electorales, con lo que la discusión que sobre la misma se haga entre los sectores más activos de la sociedad puede estar influida por esa atención que la prensa le da, aunque también - y como una cuestión diálectica del fenómeno es innegable que esa atención sucede porque los lectores se muestran interesados en ese tema más que en otros. Esto parecería más intenso en México, donde el interés de la prensa por la educación superior es mucho mayor que el dado a los otros niveles. Así, si bien la prensa de este país se interesa poco por la educación, cuando lo hace centra su mayor interés en la educación superior.

Lo anterior no niega otros intereses, pues como aparece en el Cuadro II, el nivel de educación básica fue mayoritario en el caso argentino, donde el $40 \%$ de las notas dedicadas a educación la tuvieron como referencia directa. Posiblemente esto fue así porque, entre otras cosas, mientras el proceso electoral tomaba cuerpo, dentro de la sociedad continuaba la discusión sobre los contenidos básicos comunes de la educación, que luego de una serie de consultas, discusiones, propuestas y contra propuestas, fueron aprobados, sin que por ello aquellos que se consideraban afectados - la Iglesia Católica en particular - dejaran de criticarlos, obteniendo modificaciones de última hora que reabrieron la discusión.

Destacase en este caso el comportamiento de Página 12 quien dedicó, durante el período estudiado, el $65,3 \%$ del total de sus notas educativas a la educación básica, constituyéndose en el diario que mayor interés prestó a este nivel educativo tanto a nivel nacional como en el conjunto de los diarios consultados. 
Nótase, además, el poco interés que diarios como Folha de $S$. Paulo (14,7\%) y Jornal do Brasil $(16,1)$ para el caso brasileño, y La Jornada (16,8\%) en México, manifestaron por este mismo nivel, siendo en contraposición los que más atención dieron a la educación superior en sus respectivos países.

La educación media, por su parte, fue la que menos atención recibió por parte de los medios de comunicación escrita de los tres países estudiados; siendo notorio, especialmente, en el caso argentino, donde apenas el $7 \%$ de las notas tuvieron como objeto de su información el nivel medio. Debe señalarse, además, que en el caso de Brasil muchas de las notas estuvieron centradas en la discusión sobre el aumento de las cuotas que las escuelas privadas deberían o podrían cobrar a los alumnos. Como se verá más adelante, este tema también impactó en el volumen de notas que sobre los otros niveles fueron publicadas.

Vale la pena resaltar, además, que mientras las notas referidas a las Cuestiones Generales ocuparon en Brasil un poco más de la cuarta parte de las notas dedicadas a educación, en México y Argentina ocuparon menos espacio ( $21 \%$ y $13 \%$ respectivamente), con lo que puede afirmarse que en estos dos últimos países la prensa orientó mucho más sus notas a cuestiones propias de niveles educativos específicos, tal y como se muestra en el Cuadro II.

Los datos anteriores permiten mostrar que, como fue dicho en los primeros parágrafos, la educación es una tema que de alguna manera interesa a los medios de comunicación escrita, por lo que la forma y manera com las que los temas de la misma sean presentados vendrán a influir en la opinión de los lectores, contribuyendo a la conformación de los escenarios de representación, tanto los específicos a la educación como a la política. No es fácil ni posible afirmar, sin embargo, si ese volumen de información simplemente refuerza los escenarios hegemónicos, o si de alguna manera contribuyen para la construcción de escenarios intra o contra hegemónicos, ya que para ello son necesarios análisis más finos, lo que de alguna manera intentamos adelante.

El carácter de las notas

Las materias periodísticas dedicadas a la educación también se clasificaron tomando en cuenta el carácter de las mismas, pues si, como era de esperarse, la gran mayoría de las mismas fueron notas informati- 
vas, reportajes breves o amplios sobre hechos o situaciones del sistema educativo, ya fuera sobre sus instituciones, actores o usuarios directos e indirectos, en algunos casos las páginas editoriales de los diarios ya fuera como opinión del mismo, ya como criterios de algunos de sus columnistas - emitieron opiniones sobre algunas de las cuestiones educativas que consideraban importantes para tomar posición. ${ }^{27}$

Estas últimas materias resultan interesantes en el conjunto de nuestro trabajo, pues si bien no llegan a constituir el bloque más abundante de las notas, la proporción en que aparecen, así como el nivel al que hacen referencia, pueden indicarnos de manera un poco más clara en qué forma la prensa participa en la construcción de los escenarios de representación política en los períodos previos a los eventos electorales nacionales, y si de alguna forma esos escenarios se corresponden directamente con los discursos hegemónicos.

Como puede verse en el Cuadro IV.1, es en Argentina donde en términos proporcionales, más opiniones sobre la educación se expresaron (15\%), viniendo luego Brasil (10,8\%). Mientras tanto, resulta notorio que tales temas no interesaron mayor cosa a los columnistas y editorialistas de los diarios mexicanos, siendo el país donde fue menor la proporción de notas de ese tipo dedicadas a educación $(3,9 \%)$. Ello puede tener múltiples explicaciones, sin embargo, lo que se puede descubrir a simple vista es que es en Argentina donde la educación es considerada, al menos para los medios de comunicación escrita, como una cuestión relativamente cotidiana, teniendo su opuesto en México, donde el interés de columnistas y editorialistas está muy circunstancialmente orientado a las cuestiones educativas.

Las opiniones, a su vez, tuvieron como objetos de mayor interés las cuestiones generales y la educación superior, para los casos de Argentina y Brasil, tal y como aparece en el Cuadro IV.2. Mientras en Brasil casi la mitad de las opiniones se refirieron a cuestiones generales, en Argentina la mayoría son para la educación superior. Resulta, pues, que no existe, para ninguno de los casos estudiados, una relación directa entre la importancia dada a un nivel en particular en término del total de notas y la proporción de materias de opinión dadas a un nivel en particular.

Lo anterior muestra que si los diarios atienden los distintos niveles educativos, en el caso de las opiniones las mismas tratan en su mayoría, con la excepción de México, de discutir la educación como un todo, sin tomar mucho en consideración los distintos niveles. Si bien los comentaristas hacen sus notas a partir de hechos específicos que 
ameritan comentarios, en el caso de la educación resulta claro que en el período estudiado, la mayoría de dichos comentarios si bien pudieron tener como origen cuestiones puntuales de algún nivel educativo en particular, fueron referidos a situaciones más generales.

Ahora, si centramos la atención en los distintos niveles en particular, notamos que fue la educación superior quien atrajo más la atención de columnistas-editorialistas, pues como en el mismo Cuadro IV.1 puede observarse, con la excepción de México un poco más del $10 \%$ de las notas dedicadas a ese nivel aparecieron como notas editoriales o de columnistas. Considerando esos mismos datos, resulta notorio el desinterés del que fue objeto la educación básica por parte de los columnistas-editorialistas pues, en ninguno de los tres casos estudiados, las notas de opinión ocuparon más del $10 \%$ del total de las notas dedicadas en cada país a ese nivel educativo. Si bien es en México donde menos opiniones aparecen sobre la educación, ese escaso número es mayoritariamente dedicado a la educación básica: 57\% del total de ese tipo de notas, según el Cuadro IV.2.

La educación media, por su parte, fue quien menos opiniones consiguió producir en los tres países, pues si bien en Argentina el 8,3\% de las notas de ese nivel fueron de opinión, cuando se les considera dentro del conjunto total de las opiniones se descubre que solo significaron el $4 \%$, situación que es muy semejante a la de Brasil, donde solamente el 6,2\% de todas las opiniones tuvieron como referencia directa la educación secundaria. Nótase por tanto que la prensa, y en consecuencia directa sus lectores, no consideran a la educación media como un espacio preponderante, capaz de exigir opiniones por parte de los editores y columnistas de los diarios. Si pensamos que es en ese nivel donde se capacita para el trabajo a buen número de jóvenes, la ausencia de opiniones y comentarios sobre ese nivel muestra que los problemas que en su interior se generan no son capaces de estimular la opinión de los periodistas, si no muy de vez en cuando.

Puede concluirse por tanto, que en lo que se refiere a la opinión propiamente dicha, si bien en cada país los énfasis fueron diferentes, en los tres países la educación superior fue relativamente priorizada, posiblemente porque es en el público universitario - estudiantes, egresados, profesores etc. - donde los diarios tienen su mayor mercado, y también porque de una u otra forma los comentaristas tienen una relación más directa con las instituciones de educación superior que con las de los otros niveles, ya porque son profesores de las mismas, ya porque como intelectuales tienen como referentes más próximos a los universitarios. 
Cuando de opinar sobre educación se trata, parece que la educación superior resulta un tema mucho más próximo de los periodistas. Claro es que los comentarios en casi su totalidad no se refirieron a temas especializados - eminentemente pedagógicos — orientándose más bien a cuestiones específicas y coyunturales, tales como salarios de los profesores, recursos presupuestarios dedicados por los gobiernos federales a la educación etc., temáticas que, además, se incorporan mucho más de prisa y con menor conocimiento de causa, al espacio cultural de la población.

Si la educación posee, como espacio particular de la vida social, su propio escenario de representación, resulta claro que en los países latinoamericanos estudiados, que por sus características presentan sistemas políticos más próximos de los occidentales, como Portantiero (1978) ya ha señalado, estos escenarios se vinculan de manera directa a los de la política, ya que muchas de las cuestiones que a la educación se refieren traspasan por la forma y manera en que el poder se ejerce. Si la educación es una cuestión que se inscribe en las demandas de la sociedad, la forma en que ella es tratada por la prensa incide también en las interpretaciones de la política.

Considerando las informaciones hasta acá analizadas, bien podemos decir que desde la prensa escrita es posible dar espacio al refuerzo o cuestionamiento del ER-P existente, ya que las materias de opinión pueden en buena medida servir para ello. Resulta claro además que, a pesar de insistirse en la importancia que para los tres países tiene la educación básica, son la temática general de la educación y la educación superior las que desde las páginas de la prensa se privilegiaron, con lo que los escenarios que desde ella se construyan tendrán como referentes prioritarios tales niveles.

Los temas privilegiados

En los tres países estudiados la prensa orientó su atención a un sinnúmero de temáticas educativas. Con el fin de poder encontrar algunas líneas que pudiesen permitir la comparación y el análisis, optamos por establecer una serie de temas generales a través de las cuales pudiésemos organizar las notas publicadas en diarios diferentes como los analizados.

En los tres países los diarios dedicaron buena cantidad de su espacio noticioso a cuestiones pedagógicas de las más variadas, desde la divulgación de la puesta en marcha de actividades especiales para la alfabetización de niños deficientes físicos y mentales dentro de las escuelas públi- 
cas, hasta la implementación de nuevos procedimientos de investigación en los programas de posgrado. Como se puede ver en el Cuadro V.1, esta categoría fue la que mas notas consiguió concentrar en la prensa argentina $(22,5 \%)$ y brasileña $(13,8 \%)$, no así en México, donde tal tipo de notas ocuparon el quinto lugar, absorbiendo el $7 \%$ del total.

En Argentina tal tipo de notas respondieron por el $27 \%$ de las notas dedicadas a la educación básica, Cuadro V.2, siendo innegablemente el tema que más notas acumuló en ese nivel, situación que si bien es similar en el caso brasileño, no llega a mostrar tal nivel de concentración. Para el caso de la educación superior tal tema también es mayoritario en Argentina, $21 \%$ del total de notas del nivel, notándose para Brasil un comportamiento similar a lo que sucede con la educación básica.

Este dato resulta por si mismo sorprendente, pues si bien incorpora una gama variada de notas, muestra que la prensa de dos de los países estudiados - y especialmente en Argentina - dedica buena parte de sus espacios reservados a educación a cuestiones que no son necesariamente aspectos polémicos de la vida cotidiana, sino cuestiones intrínsecamente propias de la vida escolar. Que en Argentina casi la cuarta parte de las notas periodísticas dedicadas a la educación se interesen por ello, es una muestra de que ese tipo de temas son cada vez más noticia y que resultan de relativo interés para los lectores de los diarios, situación que es mucho más notoria en el aspecto comparativo, pues si bien en Brasil también representaron el mayor número de notas, su importancia en el conjunto de las notas es casi un $10 \%$ menor que en caso argentino.

Valioso resulta también hacer notar que en el caso argentino el interés por ese tipo de nota es casi el mismo en los dos diarios tradicionales consultados, pues mientras Clarín es responsable por el $44 \%$ de las notas sobre el tema, La Nación responde por el $41 \%$, con lo que se puede afirmar que dicho tipo de informaciones - más técnicas y especializadas, así como menos coyunturales y polémicas - son supuestamente de interés de un amplio sector de lectores, pues ambos diarios tienen un mercado relativamente común. El otro diario argentino, Página 12, en cambio, sólo fue responsable por el 15,4\% del total de ese tipo de notas, lo que demuestra que en su búsqueda por ser un diario alternativo, diferente, tales temas salen de su interés cotidiano.

En el caso brasileño, por su parte, son periódicos de relativa similitud con los argentinos los que observan el mayor tipo de notas sobre cuestiones de tipo pedagógico. Mientras uno de ellos, Folha de $S$. 
Paulo, concentró el 40,4\% del total de las notas de ese tipo, el otro que le dio importancia a dichas informaciones, $O$ Globo, solamente responde por el $21 \%$ del total de las notas, porcentaje significativamente mayor al que los diarios locales presentan en conjunto: $16 \%$.

Vale la pena mencionar que para el caso argentino el $25,6 \%$ de las notas referidas a esas cuestiones pedagógicas fueron objeto de comentarios u opiniones de columnistas de los diarios, lo que contrasta el caso brasileño, donde sólo el 11,5\% de las notas pueden ser clasificadas como de opinión. Resulta claro, pues, que no sólo los diarios argentinos dedican más espacio - relativamente - a las cuestiones meramente pedagógicas, sino utilizan tales informaciones para expresar opiniones, con lo que se confirma que la prensa de dicho país se muestra mucho más proclive a considerar tales aspectos como elementos importantes de su actividad periodística, posiblemente a causa de las propias demandas del público que constituye el mercado de los propios diarios.

Con ello además se anula, en cierta forma, la afirmación de que tales notas serían puestas por los editores como "rellenos de espacio", pues aparecen, cuando son notas, en secciones especiales dedicadas a la educación y, cuando opiniones, en las páginas principales de los diarios.

Puede decirse, también, que el escenario que de la educación se construye, tiene en Argentina un componente marcadamente pedagógico, lo que podría significar también que ese énfasis pueda tener algún correlato en lo que a la constitución del ER-P se refiere, pudiéndose pensar que exigencias en ese sentido marcaran la definición de lo que vendrían a considerarse como explicaciones hegemónicas y dominantes.

En el caso brasileño dos temas muy particulares absorbieron otro alto porcentaje de notas, haciendo de la cobertura periodística sobre la educación un hecho diferente con relación a los otros dos países en estudio, dado que si bien son temas que por sus características son periódicamente recurrentes, resultan marcadamente propios de su realidad. Son el caso de las notas sobre las mensualidades de la educación privada, que para el año previo a las elecciones absorbieron el 11,3\% del total de las notas que los diarios dedicaron a la educación, y las que dieron cuenta de la realización de los concursos vestibulares, que en ese mismo período absorbieron el 9,9\% del total de las notas dedicadas a educación en los diarios seleccionados. ${ }^{28}$

Vale la pena indicar que en el primero de los casos la situación cobró un interés vital en 1994 porque dadas las altas tasas de inflación varios sectores de la sociedad comenzaron a reclamar acciones 
jurídicas que regulacen los aumentos en las cuotas mensuales de las escuelas privadas - tanto de nivel primario como secundario y superior - por lo que varias Medidas Provisionales - $\mathrm{MP}^{29}$ - fueron emitidas por el presidente de la República para regular tales situaciones, siendo algunas veces contestadas en los tribunales por las organizaciones que aglutinan a las escuelas privadas y otras por representantes de los padres de familia o por diputados de la oposición que las consideraban inconstitucionales o contrarias a los intereses que representaban.

La casi totalidad de tales notas - 87\% - concentráronse, en el caso de Brasil, en la educación media, estando las pocas que el tema acaparó en Argentina orientadas para la educación básica - 67\% —, tal y como se detalla en el Cuadro V.1.

En Brasil fue $O$ Globo quien mayor atención prestó a tal tipo de cuestión, pues del total de las notas dedicadas al tema de las mensualidades el $56 \%$ aparecieron en las páginas del mencionado diario, ${ }^{30}$ estando en segundo lugar la Folha de S. Paulo, con sólo el $23 \%$ de las mismas. Pero si bien el tema fue reiteradamente presentado en las páginas de los diarios, muy pocos comentaristas o editorialistas se interesaron por el tema: solamente el $3 \%$ del total de las notas que sobre el mismo hicieron referencia pueden ser consideradas estrictamente como de opinión, siendo necesario destacar que tales notas de opinión fueron siempre contrarias al aumento de las mensualidades, por lo que puede afirmarse que el caracter lucrativo que la educación privada pueda tener no encuentra justificativa en la prensa escrita, siendo además clara la exigencia que, desde todos los diarios, se hizo por demandar mejoras sensibles en la educación pública gratuita, como una forma de enfrentar la industria de la educación privada.

El escenario que de este tema se construyó desde la prensa, por lo tanto, no es favorable a las reglas del mercado, si no que orientado a la defensa de la educación como una responsabilidad del Estado.

Un comportamiento relativamente parecido sucedió en lo que se refiere a los concursos vestibulares, pues mientras $O$ Globo aparece con el $40,5 \%$ del total de las notas sobre el tema, la Folha de S. Paulo aportó el $29,7 \%$. Es de notar que en lo que se refiere a las notas de opinión, el tema, en números absolutos, resultó más comentado que las mensualidades, pues le correspondieron el mismo 3\% del total de notas sobre el tema, lo que quiere decir que fueron el vestibular motivo de más notas de comentario que las dedicadas a las mensualidades. 
Otros dos temas aparecieron en la prensa, esta vez con proporciones semejantes en los tres países. Son los casos de las notas dedicadas a las huelgas de los docentes y las relativas a las cuestiones salariales de los mismos propiamente dichas, ya fuese en el marco de las huelgas o no. Como se ve en el Cuadro V.1 tanto en México como en Argentina el tema de las huelgas de los profesores fue el segundo tema más noticiado por los diarios de esos países, absorbiendo más o menos la décima parte del total de notas dedicadas a educación. En Brasil, si bien su rango es más bajo, quinto lugar, el total de notas dedicadas al tema superó el $7 \%$, por lo que su importancia, si bien no fue tan alta, Ilamó la atención de los editores de los diarios consultados.

Si consideramos que las huelgas docentes tienen como punto central la cuestión salarial, es posible decir que la conjunción de tales problemáticas absorbieron la cuarta parte de las notas periodísticas en México y más o menos la séptima parte en Argentina y Brasil.

Debe hacerse notar que el tema de las huelgas fue el segundo en importancia en la prensa mexicana $(11,4 \%)$ y argentina $(9,2 \%)$, correspondiéndole en este caso el 15,7\% del total de ellas a la educación básica, tal y como se muestra en el Cuadro V.2. Las huelgas de los profesores y funcionarios de la educación superior constituyeron para el caso mexicano, el tema más atendido $(17,7 \%)$ - Cuadro V.3 - situación que no es la misma en los otros dos países estudiados, que contrasta con el 1,4\% que al tema dedica, en ese nivel, la prensa brasileña. Lo anterior no debe entenderse como que en Argentina los profesores de básica o primaria realizaron más huelgas que los de los otros países; posiblemente eso sea cierto, pero lo que nuestros datos pueden indicar es solamente la cantidad de notas que proporcionalmente la prensa dedicó a eso tema.

El tema de los salarios de los profesores tiene un comportamiento un poco diferente, pues mientras en México llega a ocupar el 31,7\% del total de notas dedicadas a la educación básica, en Brasil sólo concentró el 1,9\% del total de las notas dedicadas a la educación superior. Vale la pena hacer notar que, mientras las huelgas en la educación superior son seguidas con mucho interés en la prensa mexicana, en el tema de los salarios las notas se concentran en la educación básica, posiblemente porque en este caso los profesores amenazaron con huelgas pero no llegaron a parar sus labores, a la par de que como una maniobra electoral los candidatos se refirieron abiertamente sobre la necesidad de incrementos salariales en ese sector.

A diferencia de los otros temas, el tema de los salarios-huelgas es mucho más polémico y sujeto a interpretaciones y utilizaciones políticas, 
con lo que la manera como el mismo fue tratado por los distintos diarios resulta esclarecedor para los análisis posteriores; sin embargo, y como se muestra en el Cuadro V.1.1., pocas fueron las notas de opinión que tales temas produjeron en los períodos previos a las elecciones. Si bien en México dichos temas fueron mucho más atendidos, las opiniones fueron muy pocas (4\%) y todas ellas referidas a la cuestión salarial; mientras tanto, en Brasil, si bien proporcionalmente fueron temas menos importantes, el $7 \%$ de las mismas fueron opiniones.

Resulta innegable que el clima laboral dentro del magisterio era mucho más "complicado" en México que en los otros países, llegando a ser el tema que más notas acaparó (14\%) dentro del conjunto de diarios consultados, seguido de cerca por el tema de las huelgas docentes $(11 \%) .{ }^{31}$ Mientras que en el primer caso la mayoría de las notas fueron responsabilidad del Universal (56\%), en el caso de las huelgas quien más importancia les dio fue el diario La Jornada (74\%). Notorio fue, para el caso de las cuestiones salariales propiamente dichas, la importancia y cobertura que del Sindicato Nacional de Trabajadores de la Educación (SNTE) hizo el Universal, situación que no se vio ni en los otros diarios ni en los otros países.

En el caso brasileño, por su parte, las notas sobre las huelgas ganaron sus mayor número en la Folha de $S$. Paulo (72\%), mientras que para el caso de los salarios quién más le brindó atención fue O Globo; esto se explica porque para el primer caso la casi totalidad de las notas se refieren a las huelgas de los profesores de la red pública del estado de São Paulo, donde fueron intensas y prolongadas en el año previo a las elecciones. Por el contrario, el estado de Rio de Janeiro, sede de los diarios O Globo y Jornal do Brasil, no se vio enfrentado a huelgas docentes tan prolongadas, pero sí constantemente se hicieron críticas y se manifestó el descontento de los profesores en lo que se refería a los salarios devengados.

En Argentina, finalmente, fue el diario Clarín quien más importancia dio a los dos temas (75\% y $67 \%$ ) con lo que se puede decir que fue en ese país donde mucho más íntima fue la relación establecida entre salarios y huelgas de los profesores.

Resulta claro que estos temas tienen una significación vital en la constitución de los ER de la educación, vinculados además de manera estrecha a los ER-P. El que tanto huelgas como demandas salariales de los docentes sean simplemente noticiados, pero poco comentados, viene a signficar que siendo temás críticos, si bien la prensa considera que los 
salarios estan desfasados, no aceptan como medida de presión las huelgas docentes, con lo que su aparecimiento en las páginas de los diarios - ya como simples notas informativas, ya como materias de opinión - se compatibiliza, en mucho, con los ER hegemónicos.

En esta tónica del levantamiento de las cuestiones conflictivas dentro del ambiente educativo, un tema que para el caso argentino fue privilegiado por la prensa en el período estudiado fueron las demandas y movilizaciones estudiantiles, donde tal tema acaparó el 7,5\% del total de las notas, casi todas referidas a la educación superior, por lo que en apartado propio profundizaremos sobre las mismas; valga decir por ahora que la totalidad de las notas fueron informativas y que mientras Clarín fue responsable por el $61 \%$ de las mismas, por el resto lo fue La Nación.

Por su parte, en el caso de México un tema que fue reiterado con relativa frecuencia por la prensa (9\%) fue el referido a la calidad de la educación como una cuestión general, on la característica de que el 95\% de las notas sobre el tema fueron notas informativas, que en términos generales trasladaban a los lectores opiniones de actores importantes, ya fuese criticando dicha calidad, ya mostrándose comprometidos con su mejora, como fue el caso de los discursos de los candidatos presidenciales en sus distintas actividades proselitistas, que la prensa mexicana cubrió con relativa prolijidad. El diario que más atendió tal tema fue $L a$ Jornada (73\% de las notas).

Otro tema relevante dentro de la cobertura de la prensa mexicana a las cuestiones educativas fue el referido a los procesos electores dentro de las instituciones - nuevamente concentrado mayoritariamente en la educación superior - siendo en este caso significativa la atención que a tal tema dio La Jornada, pues concentró el 94\% del total de las notas que sobre el tema se publicaron.

Contrario a lo que podría esperarse, temas como la situación de la cobertura escolar en los distintos niveles educativos fueron poco atendidas, no pasando en ninguno de los países del 6\% del total; situación aún menos privilegiada tuvieron las materias que se refirieron a las cuestiones físicas de los planteles educativos, pues en ninguno de los países se alcanzó el 5\%.

Nótase, por lo tanto, que si bien los diarios en términos generales emiten poca opinión con relación a los temas educativos, al abordar cuestiones conflictivas, tal el caso de las huelgas, salarios, demandas estudiantiles etc. abren espacios para la discusión, pudiéndose suponer 
que son esas temáticas las que más directamente tendrían que ver con la constitución de los ER-P, pues si bien pueden estar orientados en favor del escenario hegemónico, la presentación de los hechos - de manera más directa y desde distintas fuentes - permite que el lector tome sus propias posiciones.

No podemos acá profundizar sobre la neutralidad o no de los órganos de prensa, pero resulta innegable que en temas como las cuestiones pedagógicas la disputa por el poder y el proceso de constitución de ER-P es mucho más difícil que cuando se habla de salarios, huelgas de profesores, o mensualidades escolares. En muchos de los casos la prensa intentó simplemente dar la información, sin emitir opinión sobre los hechos - como se ve en el Cuadro IV.1 la proporción de notas de opinión es más que reducida - pero a pesar de ello, el que tales informaciones lleguen a los lectores es, nos parece, un avance en el proceso de constitución de escenarios, ya que si bien son incluidas en el diario para atender intereses de grupos de lectores en particular, la forma en que tales mensajes resulten siendo decodificados por los mismos queda fuera de la intencionalidad de los editores, dado que a diferencia de la televisión, el lector puede contar con mayor libertad para analizar e interpretar las notas, dado que la línea entre realidad y ficción queda mucho más clara.

Así, si bien la cuestión educativa no resulta un tema polémico, que incite a la publicación de grandes notas y opiniones, el hecho de que reciba cierta dedicación por parte de los diarios constituye de por sí un dato importante, ya que como ha quedado mostrado, mientras algunos temas son más atendidos, otros sólo aparecen de manera tangencial y escasa. Los de mayor presencia se insertan, como causa o producto, en temarios colectivos que de forma directa o indirecta tienen que ver con los procesos políticos, ya que pueden llegar a traducirse en demandas o cuestionamientos a los concurrentes en los procesos electorales.

No nos interesamos, es cierto, por la intencionalidad que tales notas pudiesen tener, pues si bien algunas pueden ser consideradas críticas y otras favorables a gobiernos, políticas o actores en particular, lo mismo resultaba un examen de suyo riesgoso, porque ingresaríamos al campo de subjetividadades difíciles de evaluar. Una nota, escrita con el deseo de poner en evidencia comportamiento considerados erróneos, puede, por el sólo hecho de hacerlos públicos, producir opiniones en contrario, tal sería el caso, por ejemplo, de las notas publicadas con relación a la visita del entonces candidato presi- 
dencial mexicano Ernesto Zedillo al campus de la Universidad Nacional Autónoma - Unam - pues mientras unos la consideraban una "actitud democrática del candidato" otros vieron en ella una provocación y hasta "irrespeto" a la institución. Lo cierto es que con la cobertura de tal hecho, muchos lectores pudieron saber el comportamiento del candidato y no necesariamente compartir la crítica o el apoyo que el autor de la nota estuviese dando al hecho.

Con ello el papel de la prensa escrita como definidora del ER-P es más restringido, pues la televisión, a partir de su cada vez más difusa diferenciación entre ficción y realidad, ejerce un poder mucho mayor, lo que no niega, como en el en caso arriba citado, que la forma y énfasis con que un tema sea tratado viene a reforzar el ER-P hegemónico.

Valga decir, a guisa de conclusión, que, considerando la información aquí presentada, la prensa escrita trato los temas educativos, en los tres países estudiados, de manera amplia y poco prejuiciosa, lo que permite considerarla un espacio más abierto a la posible difusión y constitución de escenarios políticos intra y hasta contra hegemónicos, aún en contra de la voluntad de sus propios propietarios y directores.

Mientras en términos noticiosos los diarios se exigen cada vez más una aproximación clara con los hechos, en términos de opinión los espacios para voces no necesariamente comprometidas con el ER-P hegemónico son mucho más amplios, quedando claro que, aún en los casos más polémicos, como vendrían a ser las huelgas magisteriales, las movilizaciónes estudiantiles y las demandas salariales, la prensa escrita se constituye en una espacio en el que el conflicto con el poder político es puesto de manifiesto, existiendo cada vez más una exigencia por evitar la manipulación.

Si bien la prensa escrita no es ajena a la construcción del ER-P dominante y hegemónico, las posibilidades de que por sus páginas se expresen visiones discordantes es mayor que en la televisión, situación que es mucho más significativo si el tema es la educación, ya que ésta no encuentra mayor espacio en las franjas cotidianas de la televisión.

\section{Notas}

1. Asumimos como punto de referencia teórica, en este sentido, las elaboraciones - aún incipientes - que sobre el concepto de Escenarios de Representación Política ER-P vienen siendo presentados por Venício de Lima y colaboradores. Resulta necesario dejar constancia de nuestro agradecimiento al prof. de Lima 
por sus comentarios y opiniones, vertidas a partes de este material presentadas al Grupo de Trabajo Midia e Política de la FA de la UnB por él coordinado y en el cual participamos.

2. Tal el caso de conceptos como los de Cultura Política - CP - e Imaginario Social - IS - , pues mientras el primero queda preso en la discusión sobre las creencias políticas (Almon y Verba 1980), el segundo se pierde en las complejidades subjetivas de las relaciones simbólicas (Baczko 1991).

3. Cuando los medios de comunicación de masas, por las necesidades propias de mantenimiento y aumento de audiencias/mercados, abren espacios a visiones diferentes de la política, visiones y concepciones consideradas como ciertas pueden ser puestas en cuestión. Ejemplo significativo de esta situación es la manera en que la cuestion indígena y la democracia son discutidas en México luego de los espacios que el EZLN y el sub-comandante Marcos ganaron en los medios a partir de su aparecimiento en diciembre de 1994.

4. Porto (1995) ha avanzado en el análisis de las telenovelas, viniendo ha descubrir que en las presentadas por la red Globo, entre los años de 1993 y 1994, se nota inicialmente una clara descalificación de la política y los políticos, para luego trasladar un cierto optimismo y confianza en el futuro, actitudes coincidentes en el tiempo con la manera en que la candidatura de Fernando Henrique Cardoso iba cobrando forma. Es este uno de los filones que más a interesado a los miembros del GT Midia y Política de la FA de la UnB, siendo sobresaliente entre ellos el de Melo, Luciana e Oliveira, Renata, "A construção do ER-P na novela Pátria Minha", mimeo., Dic. 1994.

5. Así, por ejemplo, las telenovelas brasileñas contemporáneas han incluído de manera menos simplista o maniquea la cuestión de la tenencia de la tierra, abriendo espacio a narraciones que permiten a los movimientos de sin tierra expresar sus propias interpretaciones de la situación. Además, y cada vez más, tanto en México como en Argentina, la televisión debe abrir a espacios y a temáticas que rompen con los modelos de vida y de dominación imperantes, obligados sobremanera por las propias necesidades del mercado.

6. Casos Collor en los estudios de Lima $(1990,1994)$ y Reagan en el de Smith (1996).

7. Nuevamente consideramos que la irrupción del EZLN en la prensa mexicana es una muestra de la potencialidad que la prensa escrita tiene en la construcción de los ER-P contra hegemónico. En los otros dos países, más en Brasil que en Argentina, resulta innegable que la prensa escrita ha sido responsable por la puesta en escena de temas y explicaciones que dan forma a disputas intra hegemónicas, como se muestra en la crítica que desde sus columnas de opinión se hicieron, en sus momentos, a las propuestas por permitir la reelección de jefes de los ejecutivos.

8. Resulta claro que si los ER-P incluyen a la CP entre sus elementos, para la existencia de culturas políticas dependientes y hasta parroquiales 
(Almon y Verba 1980) los medios de comunicación vendrían a ser mucho más influyentes y unidireccionales, existiendo, en hipótesis, la posibilidad de que los escenarios contra hegemónicos vinieran a estar más claramente delimitados en aquellos procesos donde pueda considerarse que exista una cultura política participativa.

9. Esta afirmación es mucho más aceptable si tomamos en cuenta que, según algunos estudios realizados en el Brasil (Berndt 1994, citado por Folha de $S$. Paulo 8/8/94), la prensa es apuntada por el $37 \%$ de entrevistados como el medio de comunicación que más ha contribuido a la democratización del país, contra el $28 \%$ que se inclina por la televisión.

10. No es gratuito, así, que en la década de los ochenta y en las luchas por la democratización de la vida pública hallan surgido en México y Argentina diarios que hacen pública su vocación contra hegemónica (tal los casos de La Jornada y Página 12 respectivamente) y que ha pesar de la fuerza del discurso dominante puedan mantener en buena medida su posición. Esta situación es mucho menos expresiva en los casos de la televisión, donde si bien se encuentran franjas y contenidos contra hegemónicos, los mismos no son tan permanentes ni constantes, como sí es el caso de los diários.

11. La cadena oficial, recién privatizada, llegó a presentar, en los últimos años de su existencia, un discurso mucho más abierto que el de la cadena privada, que constantemente hizo pública su opción por el partido de gobierno, al grado de que uno de sus principales accionistas fue nombrado embajador itinerante por gobierno del presidente Salinas.

12. Luego que la dictadura militar descubrió las dificultades para mantenerse en el poder, inicio un proceso lento de apertura, en el que la elección de presidente debería ser hecho por el Congreso de la República. Ante ello la población pasó a exigir la elección por el voto directo, lo que sólo fue conseguido luego de la promulgación de la Constitución de 1984; sin embargo, a causa de la presión y movilización popular los diputados debieron descartar al candidato de los militares - Paulo Maluf - y optaron por un candidato de mayor aceptación popular: Tancredo Neves.

13. Una relación sucinta pero completa de esos intentos aparece en Waisbord El gran desfile: Campañas electorales y medios de comunicación en la Argentina. Buenos Aires, Editorial Sudamericana, 1995.

14. Una posible razón de por qué Argentina y Brasil carezcan de prensa partidaria puede encontrarse en la inestabilidad de sus sistemas políticos, pues como afirma Waisbord (1995, p. 99) para el caso argentino: "El ciclo continuo de regímenes autoritarios y democráticos desde 1930 ha imposibilitado a los partidos mantener canales consolidados de comunicación", aunque en el caso argentino hayan existido intentos, tanto por parte del Partido Justicialista (con periódicos como Democracia y Mayoría) como del Radical (con La Época y más recientemente con La Razón). En el otro extremo, la inexistencia durante tanto tiempo de un libre juego político, vino a impedir en México la presencia de tales medios de comunicación. 
15. Es famosa la actitud del ex-presidente López Portillo (1976-1982) quien, ante la crítica de algunos periódicos, manifestó públicamente que esos diarios no recibirían más anuncios pagados por los órganos oficiales. Otra manera de controlar a la prensa ha sido, como también sucedió en Argentina, a través de la venta "sin cobro inmediato" del papel necesario para las ediciones; los periódicos llegaron, en momentos difíciles, a tener grandes deudas con las empresas estatales responsables de la importación y distribución del papel. Ante el simple amago de cobrar las deudas los diarios olvidaban cualquier actitud crítica.

16. La prensa mexicana comenzó su proceso de alejamiento del régimen como consecuencia de los sucesos de 1968: así, en 1971 apareció Plural, suplemento mensual de Excelsior, cuyo ataque gubernamental fue el detonante para el intento casi constante de sectores de la prensa por crear espacios alternativas e independientes del gobierno. Sin embargo, la debilidad de las empresas periodísticas y la arrasadora capacidad del PRI/Gobierno para controlar o anular cualquier corriente de opinión crítica, hizo que muchos de esos esfuerzos fuesen pronto desactivados, cooptados o anulados en su capacidad de divulgar opiniones alternativas. Una radiografía novelada, que enfatiza los lados más obscuros de esa relación es La Guerra de Galio, de Héctor Aguilar Camín (Cal y Arena, México, 1992). Una descripción sucinta de los principales momentos de ese proceso se encuentra en Alvarez A. Virgilio, "Chiapas, los medios de comunicación y la encrucijada mexicana", en Comunicación y Política, vol I, no 1, agosto-nov. 1994, - Nova Série. Específicamente en el apartado 3 "La sumisión de los medios de comunicación" (pp. 162-165).

17. El ombudsman de la Folha de S. Paulo, Marcelo Leite, afirma que "lo que diferencia a la prensa de otras instituciones es que ella, o al menos parte de ella, es más abierta a las críticas y a perfeccionar sus propios procedimientos. No por bondad de los propietarios y editores, si no porque la transparencia y la capacidad de aprender son hoy condiciones de sobrevivencia en el mercado" (5/11/1995).

18. Para el caso brasileño es innegable que noticieros como TJ Brasil, de la cadena SBT (Sistema Brasileiro de Televisão), mantuvo mucha mayor independencia con relación al gobierno y los partidos políticos que el Jornal Nacional de la Globo, especialmente a partir del impeachment del presidente Collor, así como intentó ser más objetivo en su atención a los candidatos a la presidencia; para ello la legislación electoral ayudo en mucho, ya que exige de los medios televisivos clara imparcialidad: si un candidato o partido se considera atacado puede exigir aclaraciones que la justicia electoral debe satisfacer inmediatamente, comportamiento que se dio en muchos casos.

19. Para el caso brasileño, luego de la salida del presidente Collor, el tema más reiterado y que más discusiones presentaba en la prensa fue el referido a las cuestiones económicas - inflación, plan económico - estando acompañado de cerca por las cuestiones electorales - nominación de los candidatos, alianzas y denuncias sobre su posible honestidad (fue tan grande esa exigencia que tanto el candidato a vice-presidente del PT como del PSDB - los principales contendientes - debieron ser reemplazados debido a dudas en sus prácticas políticas). 
Para el caso de Argentina los temas económico y electoral ganaron la mayor cantidad de espacio, estando acompañados en los últimos meses previos a las elecciones por la discusión sobre los desaparecidos, confesiones públicas de los responsables y pedido de disculpas por parte de los jefes de las fuerzas armadas. En el caso mexicano, junto a las cuestiones referidas directamente a las elecciones (marcadas por el asesinato del candidato oficial Luis D. Colosio) fueron importantes los temas económicos - especialmente todo lo referido al Tratado de Libre Comercio con Estados Unidos y Canadá - y a partir de enero del 1994 el levantamiento armado sucedido en el estado de Chiapas.

20. Fueron ellos: Tarde da Bahía, Estado de Minas y Diario de Pernambuco. Es de reconocer que para la recolección de toda esa información contamos con la valiosa e inestimable cooperación de los alumnos de la disciplina Métodos y Técnicas de Pesquisa em Educación (1/94) del curso de Pedagogía de la Faculdade de Educaçion de la UnB.

21. Para el trabajo de recolección de información sobre México contamos con el apoyo de la Embajada de México en Brasil, quien nos obsequió los diarios referidos. Para su clasificación y análisis fue de valiosa importancia la colaboración de los bolsistas de Iniciación Científica otorgados por el CNPq para el GT Mídia e Política, siendo de destacar el esfuerzo de Luciana Melo, quien coordinó el proceso de selección de notas.

22. En este diario las notas periodísticas son casi constantemente firmados por Javier Rodríguez Lozano o Rosa María Chavarría, lo que hace suponer que son los dos reporteros que tienen a su cargo la sección.

23. Característica un poco semejante puede encontrarse en los diarios especializados en los aspectos económicos, tales como Ámbito Financiero en Argentina y El Financiero en México.

24. En Argentina la educación superior acaparó el 39\% de las notas, mientras la educación básica tenía el 40\% (Cf. Cuadro II).

25. Prueba a la que son sometidos todos aquellos que desean ingresar a las instituciones de educación superior, organizados y realizados por las propias IES, por lo que dependiendo de la institución así será la exigencia y prestigio del vestibular. En las localidades donde la demanda es más grande los lugares son mucho más disputados, siendo tales pruebas un evento trascendente para la vida de los futuros estudiantes, pudiendo llegar a haber hasta 90 solicitantes para un lugar, tal circunstancia hace que los mismos sean seguidos con gran interés por sectores de población próximos a la vida universitaria.

26. Cf. Cuadro II.

27. En el estudio también se discriminaron las notas cuando eran dedicadas simplemente a la divulgación de resultados o eventos educativos, firmados o "reportados" por los propios actores. Tal tipo de notas fueron en los tres casos muy escasas, por lo que no son trabajadas en el presente texto. 


\section{Cf. Cuadro V.1.}

29. En Brasil el presidente de la República tiene la capacidad de legislar de manera temporal sobre temas considerados de urgencia nacional a través de las llamadas Medidas Provisorias - MP - las cuales entran en vigor inmediatamente y deben ser conocidas, aprobadas o rechazadas por el Congreso de la República en los siguientes treinta días a su emisión en el Diario Oficial. De no ser conocidas, el Ejecutivo tiene la potestad de reeditarlas cuantas veces lo considere necesario, con lo que en muchos casos tales MP se tornan en disposiciones jurídicas de largo alcance.

30. El interés por el tema por parte de $O$ Globo fue tan elevado que el $16,2 \%$ del total de sus notas sobre educación correspondieron a la cuestión de las mensualidades.

31. Cf. Cuadro V.1.

Education and press in the electoral context: A comparative study Argentina, Brazil and Mexico

ABSTRACT: This article tries to analyse the importance that LatinAmerican press gives to education issues and the impact such subjects could have on the population during election periods. Based on the theoretical proposal of the scenarios of political representation, the most important subjects within the education area during preelection periods according to the Argentinean, Brazilian and Mexican press are presented, considering the different levels of education. 


\section{Bibliografia}

ALMON, G y VERBA S. The civic culture revisted. Boston, Little Brown and Co., 1980.

ARAGÓN, Virgilio. "Chiapas, los medios de comunicación en la encrucijada Mexicana". In: Comunicação e política no 2. Rio de Janeiro, Cebela, 1994, vol. II, Nova Série.

BACZKO, Bronislaw. Los imaginarios sociales. Buenos Aires, Nueva Visión, 1991.

GRAMSCI, Antonio. Selections from the prison notebooks. Hoare adn G.N Smith (orgs.). Nova York, International Publishers, 1971.

LIMA, Venício A. de. "Televisão e política: A hipótese sobre a eleição presidencial de 1989". Comunicação \& política № 11. Ano 9, Rio de Janeiro, Cebela, 1990.

. "Televisão e poder: A hipótese do cenário de representação da política, CR-P". In: Comunicação e Política № 1. Rio de Janeiro, Cebela, 1994, vol. I, Nova Série.

"CR-P: Novos aspectos teóricos e implicações para a análise política". In: Comunicação e Política № 3. Rio de Janeiro, Cebela, 1995, vol. I, Nova Série.

PORTANTIERO, Juan Carlos. Estudiantes y Politica en America Latina. México, siglo XXI Editores, 1978.

PORTO, Mauro P. "Telenovelas e política: O CR-P da eleição presidencial de 1994". In: Comunicação e Política no 3. Rio de Janeiro, Cebela, 1995, vol. I, Nova Série.

SARTORI, Giovanni. "Videopolítica". In: Revista Italiana di Scienza Politica. № 2. Roma, 1989, vol XIX.

SMITH Reilly, Susan. "A convergência do cenário de representação da política (CR-P) e da narrativa política: A campanha de Ronald Reagan para a Presidência dos EUA em 1980". In: Comunicação e Política № 2. Rio de Janeiro, Cebela, 1996, vol II, Nova Série.

WAISBORD, Silvio. El gran desfile: Campañas electorales y medios de comunicación en la Argentina. Buenos Aires, Editorial Sudamericana, 1995.

WILLIAMS, R. Marxismo y literatura. Rio de Janeiro, Zahar, 1979. 
Cuadro I - Diarios consultados*

segun numero de meses, notas y porcentaje de las

mismas por mes

\begin{tabular}{|c|c|c|c|c|}
\hline Periódico consultado & Meses & № Notas & Notas/mes & Porcentaje \\
\hline Brasil $^{* *} \quad O$ Globo & 18 & 295 & 16.4 & 39.5 \\
\hline Folha de S. Paulo & 18 & 238 & 13.2 & 31.7 \\
\hline Estado de S. Paulo & 12 & 75 & 6.3 & 10.0 \\
\hline Jornal do Brasil & 12 & 62 & 5.2 & 8.3 \\
\hline Otros diarios (locales) & 12 & 78 & 6.5 & 10.5 \\
\hline Total Brasil & 72 & 750 & 10.4 & 100 \\
\hline México ${ }^{\star \star \star} \quad$ La Jornada & 7 & 113 & 16.1 & 36.5 \\
\hline El Universal & 7 & 110 & 15.7 & 35.5 \\
\hline Excelsior & 7 & 87 & 12.4 & 28.0 \\
\hline Total México & 21 & 310 & 14.8 & 100 \\
\hline Argentina $^{+} \quad$ La Nación & 4.5 & 108 & 24 & 38.7 \\
\hline Clarín & 4.5 & 99 & 22 & 35.5 \\
\hline Página 12 & 4.5 & 72 & 16 & 25.8 \\
\hline Total Argentina & 13.5 & 279 & 20.7 & 100 \\
\hline TOTALES & 106.5 & 1340 & 12.6 & 100 \\
\hline
\end{tabular}

* Tanto los países como los diarios fueron clasificados en orden descendente, considerando el total de notas dedicadas a educación en el período estudiado.

** Para el caso de Brasil los diarios nacionales Folha de S. Paulo y $O$ Globo, fueron consultados diariamente, del 1/1/1993 al 30/6/1994; los otros dos nacionales: Estado de S. Paulo y Jornal do Brasil, del 1/7/1993 al 30/6/1994. Los diarios considerados de circulación más restringida, llamados aquí de locales, fueron: Tarde da Bahia, Estado de Minas y Diário de Pernambuco, y se consultaron también durante el período del 1/7/1993 al 31/6/1994, a cada tres días, escogiéndose las fechas de inicio de manera aleatoria.

*** En este caso los diarios, todos considerados como de influencia relativamente nacional, fueron consultados diariamente durante el período del 1/1/1994 al $31 / 7 / 1994$.

+ Para el caso de Argentina los diarios fueron consultados diariamente durante el período del 1/1/1995 al 14/5/1995. 
Cuadro II - Proporción de las materias publicadas según nivel educativo de referencia*

\begin{tabular}{|l|c|c|c|}
\hline Nivel de preferencia & $\begin{array}{c}\text { Argentina } \\
(\%)\end{array}$ & $\begin{array}{c}\text { Brasil } \\
(\%)\end{array}$ & $\begin{array}{c}\text { México } \\
(\%)\end{array}$ \\
\hline Cuestiones generales & 13 & 27 & 21 \\
\hline Educación básica & 40 & 25 & 22 \\
\hline Educación media & 7 & 20 & $13^{* *}$ \\
\hline Educación superior & 39 & 28 & 44 \\
\hline TOTALES & 100 & 100 & 100 \\
\hline
\end{tabular}

* Para el caso de Brasil las notas referidas al 1ํ grau fueron clasificadas en el renglón de educación básica, y las del $2^{\circ}$ grau en el de educación média. Para facilitar la lectura los niveles fueron colocados en orden ascendente, los países en orden alfabético y anuladas las fracciones decimales.

**Es necesario anotar que en México los últimos dos años de la educación media - media superior — son ofrecidos también por las universidades públicas, con lo que algunas notas referidas a ese nivel pudieron ser consideradas como parte de la educación superior. 
Cuadro III.1 - Porcentaje de materias dedicadas a educación basica según diarios consultados

\begin{tabular}{|l|c|c|c|}
\hline \multirow{2}{*}{ Periódico consultado } & Notas/mes & \multicolumn{2}{|c|}{$\begin{array}{c}\text { Porcentajes } \\
\text { (\%) }\end{array}$} \\
\cline { 3 - 4 } & & Niveles* & Nivel $^{* *}$ \\
\hline Brasil O Globo & 5.5 & 33.4 & 53.2 \\
\hline Folha de S. Paulo & 1.9 & 14.7 & 18.8 \\
\hline Estado de S. Paulo & 1.8 & 28.0 & 11.3 \\
\hline Otros diarios (loc.) & 1.8 & 26.9 & 11.3 \\
\hline Jornal do Brasil & 0.8 & 16.1 & 5.4 \\
\hline Total Brasil & 2.6 & 24.8 & 100 \\
\hline México El Universal & 4.0 & 25.5 & 41.2 \\
\hline Excelsior & 3.0 & 24.1 & 30.9 \\
\hline La Jornada & 2.7 & 16.8 & 27.9 \\
\hline Total México & 3.2 & 21.9 & 100 \\
\hline Argentina Clarín & 8.4 & 35.2 & 33.9 \\
\hline La Nación & 6.0 & 27.3 & 24.1 \\
\hline Página 12 & 10.4 & 65.3 & 42.0 \\
\hline Total Argentina & 8.3 & 40.1 & 100 \\
\hline TOTALES & 3.4 & 37.3 & - \\
\hline
\end{tabular}

* El porcentaje se refiere a la proporción de notas dedicadas por el periódico a la educación básica sobre el total de notas que publicó sobre educación en general.

${ }^{* *}$ Este porcentaje se refiere a la proporción de notas que el diario publicó sobre la educación básica, con relación al total de notas que sobre ese nivel vehicularon los diarios de los países trabajados en este estudio. 
Cuadro III.2 - Porcentaje de materias dedicadas a educación superior según diarios consultados

\begin{tabular}{|c|c|c|c|}
\hline \multirow[t]{2}{*}{ Periódico consultado } & \multirow[t]{2}{*}{ Notas/mes } & \multicolumn{2}{|c|}{$\begin{array}{c}\text { Porcentajes } \\
(\%)\end{array}$} \\
\hline & & Niveles* & Nivel $^{* *}$ \\
\hline Brasil $O$ Globo & 4.3 & 26.4 & 36.8 \\
\hline Folha de S. Paulo & 3.8 & 28.6 & 32.5 \\
\hline Estado de S. Paulo & 2.0 & 32.0 & 11.3 \\
\hline Otros diarios (loc.) & 1.8 & 28.2 & 10.5 \\
\hline Jornal do Brasil & 0.8 & 30.6 & 8.9 \\
\hline Total Brasil & 2.9 & 28.3 & 100 \\
\hline México La Jornada & 9.6 & 59.3 & 49.3 \\
\hline Excelsior & 5.4 & 43.7 & 27.9 \\
\hline El Universal & 4.4 & 28.6 & 22.8 \\
\hline Total México & 6.5 & 47.9 & 100 \\
\hline Argentina Clarín & 9.5 & 45.4 & 44.9 \\
\hline La Nación & 10.5 & 47.5 & 43.1 \\
\hline Página 12 & 3.0 & 18 & 12.0 \\
\hline Total Argentina & 8.7 & 39.1 & 100 \\
\hline TOTALES & 4.2 & 34.1 & - \\
\hline
\end{tabular}

* En este caso el porcentaje se refiere al número de notas que el periódico dedicó a la educación superior, sobre el total de notas que el mismo dedicó a la educación en su conjunto.

${ }^{* *}$ Este porcentaje se refiere a la proporción de notas que sobre la educación superior cada diario publicó con relación al total de notas que, sobre ese nivel, publicaron los diarios de los países trabajados en este estudio. 
Cuadro IV.1 - Porcentaje del tipo de notas* según nivel y país

\begin{tabular}{|l|c|c|c|c|c|c|c|c|c|c|}
\hline \multirow{2}{*}{ País/Tipo } & \multicolumn{2}{|c|}{$\begin{array}{c}\text { Cstiones } \\
\text { generales }\end{array}$} & \multicolumn{2}{c|}{$\begin{array}{c}\text { Educacion } \\
\text { basica }\end{array}$} & \multicolumn{2}{c|}{$\begin{array}{c}\text { Educacion } \\
\text { media }\end{array}$} & \multicolumn{2}{c|}{$\begin{array}{c}\text { Educacion } \\
\text { superior }\end{array}$} & \multicolumn{2}{|c|}{ Total } \\
\cline { 2 - 13 } & OP & RE & OP & RE & OP & RE & OP & RE & OP & RE \\
\hline Argentina & 35 & 65 & 9 & 90 & 8 & 92 & 16 & 84 & 15 & 85 \\
\hline Brasil & 19 & 76 & 7 & 93 & 4 & 96 & 12 & 88 & 11 & 89 \\
\hline México & 5 & 95 & 10 & 90 & - & 100 & 3 & 97 & 5 & 95 \\
\hline
\end{tabular}

* No se incluyen los porcentajes correspondientes a las notas de divulgación, dado que les correspondieron muy pocos porcentajes en todos los casos. $\mathrm{CG}=$ Cuestiones Generales; $\mathrm{EB}=$ Educación Básica; EM = Educación Media; ES = Educación Superior. OP = Opiniones periodísticas, sean estas de Editoriales de los periódicos o de sus propios columnistas; RE = Reportajes, donde se incluyen todas las notas que "dan noticia" de algún hecho o situación educativa.

Cuadro IV.2 - Notas de opinión por país según porcentaje dedicado a cada nível

\begin{tabular}{|l|c|c|c|c|c|}
\hline \multicolumn{1}{|c|}{ País } & CG & EB & EM & ES & TOTAL \\
\hline Argentina & 30.7 & 23.0 & 4.0 & 42.3 & 100 \\
\hline Brasil & 49.4 & 13.5 & 6.2 & 30.9 & 100 \\
\hline México & 14.4 & 57.0 & - & 28.6 & 100 \\
\hline
\end{tabular}




\section{Cuadro V.1 - Porcentaje de temas mas atendidos* según país y nivel}

\begin{tabular}{|c|c|c|c|c|c|c|c|c|c|c|c|c|}
\hline \multirow[t]{2}{*}{ Temas } & \multicolumn{4}{|c|}{ Brasil } & \multicolumn{4}{|c|}{ México } & \multicolumn{4}{|c|}{ Argentina } \\
\hline & $\begin{array}{c}\text { Educ. } \\
\text { Bá- } \\
\text { sica }\end{array}$ & $\begin{array}{l}\text { Educ. } \\
\text { Sup. }\end{array}$ & $\begin{array}{l}C G_{+} \\
\text {Ed M }\end{array}$ & $\begin{array}{l}\text { Rel. } \\
\text { Tot. }\end{array}$ & $\begin{array}{l}\text { Educ. } \\
\text { Bási- } \\
\text { ca }\end{array}$ & $\begin{array}{l}\text { Educ. } \\
\text { Sup. }\end{array}$ & $\begin{array}{l}C G_{+} \\
\text {Ed M }\end{array}$ & $\begin{array}{l}\text { Rel. } \\
\text { Tot. }\end{array}$ & $\begin{array}{l}\text { Educ. } \\
\text { Básica }\end{array}$ & $\begin{array}{l}\text { Educ. } \\
\text { Sup. }\end{array}$ & $\begin{array}{l}C G_{+} \\
\text {Ed M }\end{array}$ & $\begin{array}{l}\text { Rel. } \\
\text { Tot. }\end{array}$ \\
\hline Cuest. Ped. & 25.0 & 23.1 & 51.9 & 13.8 & 7.1 & 42.9 & 50.0 & 7.0 & 48.7 & 35.9 & 15.4 & 22.5 \\
\hline $\begin{array}{l}\text { Mensualidades } \\
\text { Educ. Privada }\end{array}$ & 1.2 & 11.7 & 87.1 & 11.3 & - & - & 100 & 0.5 & 66.7 & - & 33.3 & 1.7 \\
\hline Vestibular & - & 100 & - & 9.9 & - & - & - & - & 一 & - & - & - \\
\hline Huelgas doc. & 16.7 & 5.5 & 77.8 & 7.2 & 13.0 & 74.0 & 13.0 & 11.4 & 68.8 & 25.0 & 6.2 & 9.2 \\
\hline Cuest. Salario & 30.4 & 8.7 & 60.0 & 6.1 & 46.4 & 25.0 & 28.6 & 13.9 & 50.0 & 33.3 & 16.7 & 6.9 \\
\hline $\begin{array}{l}\text { Cobertura y } \\
\text { matrícula } \\
\text { escolar }\end{array}$ & 55.9 & 4.7 & 39.4 & 5.7 & 80.0 & - & 20.0 & 2.5 & 11.1 & 77.8 & 11.1 & 5.2 \\
\hline Educ. Especial & 58.3 & 8.3 & 33.4 & 4.8 & 100 & - & - & 0.5 & 100 & - & - & 1.2 \\
\hline Construcciones & 50.0 & 8.8 & 41.2 & 4.5 & 100 & - & - & 0.5 & 37.5 & 25.0 & 37.5 & 4.6 \\
\hline $\begin{array}{l}\text { Demandas } \\
\text { Estudiantiles }\end{array}$ & - & 70.4 & 29.6 & 3.6 & - & 100 & - & 3.5 & - & 7.7 & 92.3 & 7.5 \\
\hline $\begin{array}{l}\text { Asistencia y } \\
\text { apoyo al est. }\end{array}$ & 53.8 & 23.1 & 23.1 & 3.5 & 100 & - & - & 0.5 & 100 & - & - & 2.9 \\
\hline Financiamiento & 15.4 & 30.8 & 53.8 & 3.5 & 11.2 & 44.4 & 44.4 & 4.5 & 25.0 & 33.3 & 41.7 & 6.9 \\
\hline $\begin{array}{l}\text { Leyes } \\
\text { educación }\end{array}$ & 17.6 & 11.8 & 70.6 & 2.3 & - & 58.3 & 41.7 & 6.0 & 9.1 & 81.8 & 9.1 & 6.4 \\
\hline $\begin{array}{l}\text { Formación de } \\
\text { profesores }\end{array}$ & 40.0 & 13.3 & 46.7 & 2.0 & 75.0 & - & 25.0 & 2.0 & 25.0 & - & 75.0 & 4.6 \\
\hline Calidad educ. & 73.4 & 13.3 & 13.3 & 2.0 & 5.6 & 33.3 & 61.1 & 9.0 & 33.3 & 33.3 & 33.4 & 3.4 \\
\hline Elec. Aut. Int. & 27.3 & 54.5 & 18.2 & 1.5 & 6.3 & 93.7 & - & 8.0 & - & 25.0 & 75.0 & 2.3 \\
\hline$\%$ del total & 77.4 & 79.2 & 85.5 & 81.7 & 78.0 & 66.7 & 67.2 & 69.8 & 81.4 & 86.8 & 88.6 & 85.3 \\
\hline Otros temas & 22.6 & 20.8 & 14.5 & 18.3 & 22.0 & 33.3 & 32.8 & 30.2 & 18.6 & 13.2 & 11.4 & 14.7 \\
\hline$\%$ del nivel & 24.8 & 28.3 & 46.9 & 100 & 21.9 & 43.8 & 34.3 & 100 & 40.4 & 39.3 & 20.3 & 100 \\
\hline
\end{tabular}

* Se ha escogido como punto de referencia el Brasil por ser el país del que más diarios se estudiaron y durante un período más largo. En Educ. Básica inclúyese los datos referidos al primero grau en Brasil, que consta de ocho "series", es decir, dos años más que en México y Argentina. En Educ.Sup. - nivel superior - (para el caso de México se incluyen algunas notas sobre la educación media superior, que en algunos casos es atendida también por instituciones universitarias públicas). $C G+E d M$ es la suma de las proporciones de notas correspondientes a Cuestiones Generales y al Nivel Medio (para el caso de Brasil se refiere a segundo grau); estas tres columnas sumadas para cada tema totalizan 100. Finalmente, en la columna Rel. Tot. hemos anotado el porcentaje que el tema constituye dentro del total de temas de cada país. 
Cuadro V.1.1 - Porcentaje de notas según tipo en el tema salarios-huelgas

\begin{tabular}{|l|c|c|c|c|c|c|}
\hline \multirow{2}{*}{ Tema } & \multicolumn{2}{|c|}{ Brasil } & \multicolumn{2}{c|}{ México } & \multicolumn{2}{c|}{ Argentina } \\
\cline { 2 - 7 } & OP & $\mathrm{R}$ & OP & $\mathrm{R}$ & OP & $\mathrm{R}$ \\
\hline Huelgas & 6 & 94 & - & 100 & - & 100 \\
\hline Salarios & 9 & 91 & 7 & 93 & - & 100 \\
\hline Demandas estudiantiles & 7 & 93 & 29 & 71 & - & 100 \\
\hline TOTAL & 7 & 93 & 6 & 94 & - & 100 \\
\hline
\end{tabular}

Nota: OP = Notas de opinión, tanto de columnistas como editorial.

$\mathrm{R}=$ Reportajes, que incluyen notas de simple información (cobertura de las fuentes) y entrevistas.

Los datos refiérense a la proporción de notas que, del total referidas al tema, fueron de un tipo $u$ otro. El total hace referencia a esas proporciones considerando los dos temas como uno solo. 
Cuadro V.2 - Proporción de temas más atendidos* por la prensa referidos a la educación basica según país

\begin{tabular}{|l|c|c|c|c|c|c|}
\hline \multirow{2}{*}{ Temas } & \multicolumn{2}{|c|}{ Brasil } & \multicolumn{2}{c|}{ México } & \multicolumn{2}{c|}{ Argentina } \\
\cline { 2 - 8 } & $\begin{array}{c}\% \text { del } \\
\text { nivel }\end{array}$ & $\begin{array}{c}\% \text { del } \\
\text { total }\end{array}$ & $\begin{array}{c}\% \text { del } \\
\text { nivel }\end{array}$ & $\begin{array}{c}\% \text { del } \\
\text { total }\end{array}$ & $\begin{array}{c}\% \text { del } \\
\text { nivel }\end{array}$ & $\begin{array}{c}\% \text { del } \\
\text { total }\end{array}$ \\
\hline Cuestiones pedagógicas & 14.0 & 13.8 & 2.4 & 7.0 & 27.1 & 22.5 \\
\hline Cobertura y matrícula & 12.9 & 5.7 & 9.8 & 2.5 & 1.4 & 5.2 \\
\hline Educación especial & 11.2 & 4.8 & 2.4 & 0.5 & 2.9 & 1.2 \\
\hline Construcciones y equipo & 9.2 & 4.5 & 2.4 & 0.5 & 4.3 & 4.6 \\
\hline Asistencia y apoyos & 7.5 & 3.5 & 2.4 & 0.5 & 7.1 & 2.9 \\
\hline Cuestiones salariales & 7.5 & 6.1 & 31.7 & 13.9 & 8.6 & 6.9 \\
\hline $\begin{array}{l}\text { Ampliación de planta } \\
\text { docente }\end{array}$ & 5.4 & 2.5 & - & - & 4.3 & 1.7 \\
\hline Deserción y repitencia & 5.4 & 1.4 & 2.4 & 0.5 & - & - \\
\hline $\begin{array}{l}\text { Huelgas y paros } \\
\text { docentes }\end{array}$ & 4.8 & 7.2 & 7.3 & 11.4 & 15.7 & 9.2 \\
\hline Formación de profesores & 3.3 & 2.0 & 7.3 & 2.0 & 2.9 & 4.6 \\
\hline Total columna & 81.2 & 51.5 & 68.1 & 38.8 & 74.3 & 58.8 \\
\hline Otros temas & 18.8 & 48.5 & 31.9 & 61.2 & 25.7 & 41.2 \\
\hline TOTALES & 100 & 100 & 100 & 100 & 100 & 100 \\
\hline
\end{tabular}

* Se ha escogido como punto de referencia el Brasil por ser el país del que más diarios se estudiaron y durante un período más largo. Como primera referencia se tomaron en cuenta aquellos temas que ocupando los rangos de más atendidos sumaban el $75 \%$ de las notas del país base (Brasil), agregándoseles aquellos temas que en los otros países ocupan también los rangos principales. 
Cuadro V.3

Proporción de temas mas atendidos* por la prensa referidos a la educación superior según país

\begin{tabular}{|l|c|c|c|c|c|c|}
\hline \multirow{2}{*}{ Temas } & \multicolumn{2}{|c|}{ Brasil } & \multicolumn{2}{c|}{ México } & \multicolumn{2}{c|}{ Argentina } \\
\cline { 2 - 7 } & $\begin{array}{c}\text { \% del } \\
\text { Nivel }\end{array}$ & $\begin{array}{c}\text { \% del } \\
\text { Total }\end{array}$ & $\begin{array}{c}\text { \% del } \\
\text { Nivel }\end{array}$ & $\begin{array}{c}\% \text { del } \\
\text { Total }\end{array}$ & $\begin{array}{c}\% \text { del } \\
\text { Nivel }\end{array}$ & $\begin{array}{c}\text { \% del } \\
\text { Total }\end{array}$ \\
\hline Vestibular & 34.9 & 9.9 & - & - & - & - \\
\hline Cuestiones pedagógicas & 11.3 & 13.8 & 6.3 & 7.0 & 20.6 & 22.5 \\
\hline Demandas estudiantiles & 9.0 & 3.6 & 7.3 & 3.5 & 17.6 & 7.5 \\
\hline Investigación científica & 6.1 & 2.0 & 3.1 & 1.5 & 1.5 & 0.6 \\
\hline $\begin{array}{l}\text { Relaciones universidad- } \\
\text { empresa }\end{array}$ & 6.1 & 2.0 & 2.1 & 1.0 & - & - \\
\hline $\begin{array}{l}\text { Mensualidades } \\
\text { educación Privada }\end{array}$ & 4.7 & 12.0 & - & 0.5 & - & 1.7 \\
\hline $\begin{array}{l}\text { Financiamiento de la } \\
\text { educación }\end{array}$ & 3.8 & 3.5 & 4.2 & 4.5 & 5.9 & 6.9 \\
\hline $\begin{array}{l}\text { Huelgas de profes. y } \\
\text { func. }\end{array}$ & 1.4 & 7.2 & 17.7 & 11.4 & 5.9 & 9.2 \\
\hline $\begin{array}{l}\text { Elecciones de } \\
\text { autoridades int. }\end{array}$ & 2.8 & 1.5 & 15.6 & 8.0 & 1.5 & 2.3 \\
\hline Cuestiones legales & 0.9 & 2.3 & 7.3 & 6.0 & 13.2 & 6.4 \\
\hline Cuestiones salariales & 1.9 & 6.1 & 7.3 & 13.9 & 5.9 & 6.9 \\
\hline Cobertura y matrícula & 0.9 & 5.7 & - & 2.5 & 10.2 & 5.2 \\
\hline Total columna & 83.8 & 59.6 & 70.9 & 59.8 & 82.3 & 69.2 \\
\hline Otros temas & 16.2 & 40.4 & 29.1 & 40.2 & 17.7 & 30.8 \\
\hline TOTALES & 100 & 100 & 100 & 100 & 100 & 100 \\
\hline
\end{tabular}

* Se ha escogido como punto de referencia el Brasil por ser el país del que más diarios se estudiaron y durante un período más largo. Como primera referencia se tomaron en cuenta aquellos temas que ocupando los rangos de más atendidos sumaban el $75 \%$ de las notas del país base (Brasil), agregándoseles aquellos temas que en los otros países ocupan también los rangos principales. 